\title{
Cascading Utilization of Wood: a Matter of Circular Economy?
}

\author{
Claudia Mair ${ }^{1}$ - Tobias Stern ${ }^{1}$
}

Published online: 30 August 2017

(C) The Author(s) 2017. This article is an open access publication

\begin{abstract}
Purpose of Review The aim of this study was to analyze the differences and similarities between the concepts circular economy (CE) and cascading utilization (CU) and the interactions between these concepts. The method chosen for this study was a qualitative content analysis, which was conducted on academic CU publications that appeared between 1990 and 2016. To identify connections between $\mathrm{CU}$ and $\mathrm{CE}$, the findings of this study are compared to the results of a recent review on CE.

Recent Findings From the perspective of the broader goals of $\mathrm{CE}$ and $\mathrm{CU}$, both concepts promise to increase resource efficiency by supporting the multiple use of a resource. Research conducted on both concepts has included analyses of the environmental impacts of the $\mathrm{CU}$ or CE systems and descriptions of frameworks and tools used to develop cascade chains or measure the circularity of a given resource. Even though the concepts have many similarities, the research has mostly been conducted independently, and the number of connections between the two concepts is surprisingly low.

Summary In general, the results of the analysis supported the hypothesis that $\mathrm{CU}$ and $\mathrm{CE}$ have many parallels and similarities. The $\mathrm{CU}$ concept addresses primarily resource management whereas CE provides a more holistic approach. Practically, the publications on CE include considerations of many kinds of resources, whereas publications on $\mathrm{CU}$ include a stronger focus on bio-based materials. Despite these differences, $\mathrm{CU}$ was
\end{abstract}

This article is part of the Topical Collection on Forest Policy, Economics and Social Research

Claudia Mair

claudia.mair@uni-graz.at

1 Institute of Systems Sciences, Innovation and Sustainability Research, University of Graz, Graz, Austria shown to clearly fit into the $\mathrm{CE}$ concept in that it provides a specific focus on the utilization possibilities (e.g., reuse, recycling, and up-cycling) of a given resource. The term $\mathrm{CU}$ may be used whenever one or more of these measures are used.

Keywords Cascading utilization · Circular economy - Waste hierarchy $\cdot$ Resource efficiency $\cdot$ Bio-economy

\section{Introduction}

Worldwide, discussions are ongoing about the mitigation of emissions and efficient use of resources, renewable, and nonrenewables. In an effort to address these challenges, a few concepts have been proposed which promise to guide the current economic and environmental situations towards a more sustainable future (e.g., a circular economy or bio-based economy). Bezama [1] mentioned that both the circular economy and the bio-economy strategies have the circular management of resources in common. The circular economy (CE) suggests closing material flows in productive systems to maximize the utilization of available resources.

The bio-economy strategy of the European Commission [2] promotes the cascading use (CU) of biomass and biobased waste streams, which has been described as a valueadded hierarchical utilization of biomass [1]. A focus has been placed only on products that are wholly or partly derived from materials of biological origin [2].

Interestingly, the CU of wood as well as of other kinds of biomass gained growing importance in Europe. Several research projects have focused on $\mathrm{CU}$, for instance, within a study on the CU of recovered wood [3], optimized cascade use of wood [4•], cascade use of wood products [5], efficient use of wood in cascades vs. energy, [6] or CU of renewable resources [7]. 
This illustrates that the concept of cascading utilization is mostly mentioned in the context of biomass or bio-based materials, although Sirkin and ten Houten [8] stated that the cascade chain concept should be applicable to the utilization of all resources. CE, on the other hand, includes all types of resources (i.e., renewable as well as non-renewable resources) [9].

Bezama [1] argued that although the concept of CU has been identified as one of the cornerstones of the bioeconomy and CE, a critical discussion in terms of what cascading is and how it influences both strategies is needed.

\section{Cascading Utilization}

Sirkin and ten Houten [8, p. 215] describe the cascade chain as a "theoretical notion which integrates concepts of resource economy and sustainability into an operational framework for determining the efficiency and appropriateness of a given resource exploitation in a given context." Mantau [10, p. 36] defines a cascade use "as multiple use of the wood resources from trees by using residues, recycling (utilization in production) resources or recovered resources (collected after consumption)."

The European Commission [4•] reviewed the current literature on cascading, in order to define the $\mathrm{CU}$ of wood and assess the environmental and social impacts of cascading. The results show that until now, there has been a general lack of consensus on how to define $\mathrm{CU}$, but common elements in the different conceptual understandings of CU can be identified. The differences in the definitions of $\mathrm{CU}$ refer to the kind of biomass included, whether a single stage or multiple stages are allowed as a cascading principle, whether CU is strictly descriptive or encompasses a strategic perspective, or whether the value and quality of the cascaded material are considered. Hereby, most of the definitions of CU include material down-cycling (decreasing quality), closed-loop recycling (unchanging quality), and material up-cycling (increasing quality) $[4 \cdot, 5]$.

Based on the study published by the European Commission [4•], a functional definition of $\mathrm{CU}$ is provided as follows: "Cascading use is the efficient utilization of resources by using residues and recycled materials for material use to extend total biomass availability within a given system" $[4 \bullet$, p. 10].

The technical definition of cascading applies when

- "Wood is processed into a product and this product is used at least once more either for material or energy purposes;

- In a single stage cascade, the wood is processed into a product and this product is used once more for energy purposes.

- In a multi-stage cascade, the wood is processed into a product and this product is used at least once more in material form before disposal or recovery for energy purposes" $[4 \cdot$, p. 10].

Cascading utilization is not only applicable to wood but also, in general, to biomass. Haberl and Geissler [11] state that the socioeconomic advantage, which can be gathered from a limited amount of resources, can be maximized through increasing the efficiency of a resource by means of CU. With reference to biomass, this would mean that it "should be first used for food, then for high value added products (including re-use and recycling) and afterwards as a source for bioenergy and biofuels" [12, p. 3]. Likewise, the European Commission $[13,14]$ promotes the CU of biomass within the CE strategy, but again only biomass is considered as the object.

Despite the fact that research has steadily been conducted on $\mathrm{CU}$, consensus over its meaning is still lacking [4•]. It is also difficult to draw system boundaries around cascading definitions to clearly separate $\mathrm{CU}$ from other resource and waste management concepts, such as the waste hierarchy implemented under the EU Waste Framework Directive (Directive 2008/98/EC) [4•]. Furthermore, overlaps between the concepts of CU and CE occur [5].

\section{Circular Economy}

The idea of an economy as a circular system was first developed by Boulding in 1966 [15], who basically said that a closed system, which virtually did not exchange matter with the outside environment, is the prerequisite for the sustainability of human life on earth $[16,17 \cdot]$. The conceptual framework of CE, however, was initially formulated by Pearce and Turner in 1989 [18]. The shift from the traditional open-ended economic system to the circular economic system has subsequently been discussed $[17 \cdot, 19]$.

A CE is a system that allows the added value in products to be kept for as long as possible and in which waste is eliminated. When a product has reached the end of its life, the resource is kept within the economy, so that the product or component is used multiple times and, consequently, creates further value [13]. Yuan et al. [20, p. 5] argue that "the core of $\mathrm{CE}$ is the circular (closed) flow of materials and the use of raw materials and energy through multiple phases."

Since its theoretical foundation, a steady flow of research has been dedicated to CE. In particular, the annual number of publications significantly increased from 2005 to 2015 . The largest share of CE research has focused on China (e.g., [20-23]), but many other geographically-independent studies, as well as studies in other regions such as Europe or Thailand $[17 \cdot, 24 \bullet \cdot]$, did research referring to CE.

CE has been implemented at the policy level in countries such as China and Japan. The European Union has promoted the concept through the Circular Economy Package [17•]. Waste management plays a central role in the $\mathrm{CE}$ implementation in Europe. A waste hierarchy approach, for instance, was established within the EU Waste Framework Directive, with a priority order for managing resources starting with waste prevention, preparation for reuse, recycling, and energy recovery to disposal (Directive 2008/98/EC) [14]. 
The concept of CE, however, extends far beyond waste management. The Ellen MacArthur Foundation [24••, p. 7] defines a $\mathrm{CE}$ "as an industrial system that is restorative and regenerative by intention and design." It describes $\mathrm{CE}$ as a system, which 'replaces the 'end-of-life' concept with restoration, shifts towards the use of renewable energy, eliminates the use of toxic chemicals, which impair reuse, and aims for the elimination of waste through the superior design of materials, products, systems, and, within this, business models" [25, p. 7].

A CE is basically based on the three principles, widely known as the $3 \mathrm{R}$ principles, namely, reduction, reuse, and recycling [23]. Within the CE theory, the term cascade is also used. Hereby, the material is cascaded through further applications to extract additional value from the resource. However, only biological material is considered [9], as is the case in most of the literature on cascading [4•].

Hence, it can be said that the core of the CE as well as the $\mathrm{CU}$ concepts is to use materials and products multiple times to increase the utilization time and resource efficiency. Surprisingly, both concepts are rarely mentioned in the same context, when a review of literature indexed in scientific databases is conducted. Only Bezama [1] mentioned the concepts in his editorial and noted that cascading has been identified as a cornerstone of the strategies on bio-economy and CE.

Therefore, the objective of this study was to analyze the differences or similarities between these concepts. We asked the following questions: What characterizes each concept and how do these concepts interact? Can the research results on $\mathrm{CU}$ be used to enhance the concept of CE or vice versa?

\section{Research Methodology}

Initially, a literature research was conducted on $\mathrm{CE}$ publications to identify the characteristics of the CE concept. Two recent reviews on $\mathrm{CE}$ publications $[17 \bullet, 24 \bullet \bullet]$ were identified as particularly helpful in that they allowed us to identify criteria that could be used to further analyze the publications on CU. Next, a systematic review on academic literature on CU was carried out. The identified publications on CU were then analyzed with reference to the identified CE criteria. Afterwards, the results were compared to the results reported in a review on CE by Lieder and Rashid [24••], who used similar methods to review the literature on CE.

The method chosen for this study was a qualitative content analysis described by Mayring [26], which relied upon the software support of MAXQDA [27]. The software was used to code the identified publications on CU by applying the selected (CE) criteria, which are summarized in Table 1.

In the following section, the procedure used to identify relevant publications as well as the descriptions of the criteria chosen to analyze the publications on $\mathrm{CU}$ is explained more in detail.

\section{Data}

To identify relevant scientific literature, the scientific databases Scopus and ScienceDirect were searched. The literature search was conducted in December 2016, and the following key words were used: cascade, cascading, cascaded, or cascades in combination with use, using, utilization, or chain. These words were entered in combination with the terms wood, biomass, resource, material, product, or waste. A detailed description of the search queries and the literature search procedure can be found in the Appendix.

Since Sirkin and ten Houten [8] are considered to be pioneers of the CU concept [4•] and Pearce and Turner [18] are regarded as the researchers who developed the conceptual framework of CE [17•, 19], the time boundaries were set from 1990 to 2016.

Although the term cascading utilization has become quite popular in the German-speaking regions of Europe during the past few years, the search was limited to scientific articles written in English, since most of the scientific articles in the mentioned databases were in English. Moreover, the filters in the Scopus and ScienceDirect databases were set to article, review, and editorial.

Combining all the above-mentioned key words in a single string and applying the time and document type filters in Scopus resulted in the identification of over 15,000 potentially relevant documents. This was possibly because the term cascade is used not only in the context of resource utilization but also in the context of energy, water, and many other fields. Therefore, irrelevant subject areas were excluded through the application of various filters, and the search was limited to the search query "cascade* AND (use OR utilization OR chain)" in combination with the various types of resources.

This search resulted in the identification of 213 potentially relevant articles in ScienceDirect and 113 articles in Scopus. The abstracts of these articles were screened to determine whether CU was mentioned in a context with resource management and, therefore, would be considered relevant for the purpose of this study. Furthermore, only articles that mentioned the term cascade more than three times in the text were included. To assure that most of the relevant cascading literature was included, the reference lists of the articles gathered during this process were screened to identify additional, potentially relevant publications. Finally, all duplicates were removed, which resulted in the collection of a pool of 57 articles for further analysis.

\section{Analysis}

At the beginning of the analysis, all articles were clustered geographically to identify where most of the research on 
Table 1 Criteria used to analyze the cascading literature

\begin{tabular}{|c|c|c|c|c|}
\hline Research field & & & Type of research & Research perspectives \\
\hline Industrial ecology & Environmental science & Management and economics & Review studies & Resource scarcity \\
\hline Business management & Supply chain management & Sustainability research & Specific studies & Environmental impact \\
\hline Process engineering & Management and law & Social science & Development work & Economic benefits \\
\hline Geographical distribution & & Publication date & Cascading dimension & \\
\hline Geographically independent & Asia & 1990-2016 & Utilization time & Resource salvageability \\
\hline North America & Europe & & Resource quality & Consumption rate \\
\hline \multicolumn{5}{|c|}{ Circular economy and waste management principles (3R and $\mathrm{WH}$ ) } \\
\hline Reduce & Reuse & Recycle & Recovery & Disposal \\
\hline \multicolumn{5}{|l|}{ Type of resources } \\
\hline Renewable resources & & Resources & Non-renewable resources & \\
\hline
\end{tabular}

cascading has been conducted. The publication dates of the articles were analyzed to identify publication peaks and, more generally, to gain an overview of how the interest about the CU concept has developed over the years. A similar analysis of the geographical distribution and publication timeline for CE literature was done by Lieder and Rashid [24••] and Ghisellini et al. [17•]. These authors performed a literature review on publications about $\mathrm{CE}$ and not only provided a very good overview of $\mathrm{CE}$ research but also were relevant in that they allowed us to identify criteria that could be used to categorize the cascading literature. Since the focus of this study was not to review cascading literature but to identify linkages and differences between $\mathrm{CE}$ and CU, the categories chosen by Lieder and Rashid [24••] were considered to be appropriate for classifying the literature on $\mathrm{CU}$ as well. Based on this review on $\mathrm{CE}$, the following criteria were selected: (1) geographical distribution, (2) publication date, (3) research field, (4) type of research, and (5) research perspective. An overview of these criteria is given in Table 1.

The criterion research field was adapted from the analysis on literature about CE performed by Lieder and Rashid [24••] and included fields such as industrial ecology, sustainability research, and environmental science (Table 1).

The category type of research included the following types of literature [24••]: Review studies on previously published literature, which may include discussions on existing concepts to propose new ones; Specific studies limited to particular industries and/or geographic regions including empirical analyses. This latter type of research also potentially contained experimental setups; and Development work resulting in the identification of frameworks, tools, models, and methods for decision-making support towards CE implementation. This type of research potentially included conceptual as well as empirical studies that motivated the purpose of the development. The perspectives from which $\mathrm{CE}$ has been researched are resource scarcity, environmental impact, and economic benefit and are considered to be appropriate for the analysis of CU literature. Lieder and Rashid
[24••] described these perspectives as follows: The perspective resource scarcity includes articles in which the research topic or motivation is the critical nature of materials or resource productivity. The articles were allocated to the perspective of environmental impact if solid waste, landfill, emissions, or pollution was the reason for carrying out the study. Lastly, the perspective of economic benefits was assigned if the researchers also considered financial aspects.

In addition to the above-mentioned criteria, two more categories were included: the $3 R$ principles from $C E$ and the cascading dimensions of CU introduced by Sirkin and ten Houten [8]. The concept of CE follows the principles of reducing resource use, reusing, and recycling, which are also called the 3R principles [21]. Feng and Yan [20, p. 95] describe the objectives of those principles as "reducing the resources that enter the production process, effecting multiple use of the same resources in different ways, and reusing waste from one facility as a resource for other facilities."

Since some CU definitions include aspects of up- and down-cycling as well as aspects of closed loop recycling for materials [4•], the $3 \mathrm{R}$ principles were also used during the analysis of literature on CU. Furthermore, the concept of CU includes the energy production of end-of-life materials, which is part of the waste hierarchy (WH) but not the $3 \mathrm{R}$ principles. Therefore, the waste hierarchy elements - prevention and preparing for reuse, recycling, recovery, and disposal - are also included as criteria. Another argument for including the waste hierarchy elements is because the cascading principle is already included in the waste hierarchy to some extent when it refers to prioritizing the reuse of waste materials [28, 29]. The 3 Rs as well as the waste hierarchy elements are defined in Table 2 according to the European Union descriptions [30].

The second waste hierarchy element is called preparing for reuse and is described as "checking, cleaning or repairing recovery operations, by which products or components of products that have become waste are prepared so that they can be re- 
Table 2 Definition of the 3R principles and the waste hierarchy elements [30]

\begin{tabular}{|c|c|c|}
\hline Principle & Code & Definition \\
\hline Reduce & $\begin{array}{l}\text { 3R and } \\
\text { WH1 }\end{array}$ & $\begin{array}{l}\text { Aims to reduce the inputs of resources, energy, materials, and other resources in the pre-manufacturing and manufacturing } \\
\text { stages and promotes the reduction of emission and waste during the use stage }[17,19] \text {. The first stage of the waste hierarchy } \\
\text { addresses the reduction of waste, harmful substances, and adverse impacts through waste [30]. }\end{array}$ \\
\hline Reuse & $\begin{array}{l}3 \mathrm{R} \text { and } \\
\text { WH2 }\end{array}$ & $\begin{array}{l}\text { Is defined as "any operation by which products or components are used again for the same purpose for which they were } \\
\text { conceived" [30, L312/10] }\end{array}$ \\
\hline Recycle & $\begin{array}{l}\text { 3R and } \\
\text { WH3 }\end{array}$ & $\begin{array}{l}\text { "Means any recovery operation by which waste materials are reprocessed into products, materials or substances whether for the } \\
\text { original or other purposes" }[30, \mathrm{~L} 312 / 10]\end{array}$ \\
\hline Recovery & WH4 & $\begin{array}{l}\text { Means any operation in which waste serves a useful purpose, such as using the waste as fuel or other means to generate energy } \\
\text { [30] }\end{array}$ \\
\hline Disposal & WH5 & $\begin{array}{l}\text { Is defined as any operation which is not a recovery operation, such as a landfill, in which waste is released into water bodies or } \\
\text { seas or incinerated [30] }\end{array}$ \\
\hline
\end{tabular}

used without any other pre-processing" [30, L 312/10]. For simplification, this element is assumed to be congruent with the $3 \mathrm{R}$ principle reuse.

To differentiate the CU concept from the CE concept, we investigated whether the $\mathrm{CU}$ literature referred in any way to the elements of the "four dimensional model for resource economy" proposed by Sirkin and ten Houten [8], which are as follows:

1. Resource quality, which refers to the quality of a resource within the cascade chain and implies that a resource should be used again for a purpose with the highest possible demands or value creation;

2. Utilization time, which describes the whole time span over which a resource has been utilized;

3. Resource salvageability, which is defined as "the degree to which the resource qualities of a substance, material or product can be recirculated" [8, p. 217]; and

4. Consumption rate, which considers the volume or rate of a resource flow.

To identify the interrelations between the concepts, we analyzed how often and to which elements the CU authors referred to the original CU model proposed by Sirkin and ten Houten [8]. The same was held true for the 3R principles and waste hierarchy elements. If they appeared frequently in the $\mathrm{CU}$ articles, we assumed that this was indicative of a high degree of similarity between the concepts. In this way, these results of the analysis helped us identify whether the CU concept was different from $\mathrm{CE}$ and how.

\section{Results}

\section{Cascading Utilization-a Literature Overview}

Not all the analyzed cascading literature had a primary research focus on the CU concept. CU was often only mentioned secondarily, as in Gasol et al. [31], Ariffin et al. [32], or Böttcher et al. [33]. In addition, some studies only mentioned the term cascading [34-38], but did not define what was understood when using the term.

Nevertheless, these articles can also provide important information for future CU research. For example, Gasol et al. [31] analyzed the environmental impacts of different reuse systems. These articles were also included in this analysis [30].

Table 3 provides an overview of the CU publications included in this review. The editorial written by Geldermann et al. [39] was also included because it was published in a special issue that focused on "Improved Resource Efficiency and Cascading Utilization of Renewable Materials."

The review studies provided an overview of which role wood polymer composites (WPCs) could play in the utilization cascade of the wood industry [40] and, more generally, how the bio-economy is currently developing in Europe [41], as well as the development and application of relevant biomasses [42]. Gustavsson and Sathre [43] discussed the definition of an appropriate functional unit and effective system boundaries that could be used to analyze the energy and carbon implications of substituting wood for non-wood materials in buildings. Knauf [44] asked whether the stated benefits of cascade use of wood should be fundamentally questioned when considering the conflicts between the European energy policy, which considers biomass to be a key energy carrier, and the EU waste framework directive, which prioritizes all kinds of waste handling. Sikkema et al. discussed the support of sustainable and efficient wood sourcing practices needed to reach a European bio-economy [45].

In terms of development studies, publications that described normative and theoretical works, methods, and models as well as frameworks were included in this review.

The theoretical foundation for cascading utilization was provided by Sirkin and ten Houten [8], whereas Reijnders [49] proposed an outline of a normative strategy for sustainable resource choice and recycling. Another interesting 
Table 3 Analyzed CU articles categorized into types of research

\begin{tabular}{|c|c|}
\hline Editorial (1) & Geldermann et al. [39] \\
\hline Review studies (9) & $\begin{array}{l}\text { Teuber et al. [40]; de Besi and McCormick [41]; Brosowski et al. [42]; Gustavsson and Sathre [43]; Knauf [44]; Sikkema et al. } \\
\text { [45]; Lippke et al. [46]; Brunet-Navarro et al. [47]; van Lancker et al. [48] }\end{array}$ \\
\hline $\begin{array}{l}\text { Development work } \\
\text { (14) }\end{array}$ & $\begin{array}{l}\text { Sirkin and ten Houten [8]; Mantau [10]; Reijnders [49]; Connelly and Koshland [50]; Kim et al. [51]; Yamashita et al. [52]; Knauf } \\
\text { [53]; Mellor et al. [54]; Vogtländer et al. [55]; Dornburg and Faaij [56]; Keegan et al. [57]; McLaren et al. [58]; Lafleur and } \\
\text { Fraanje [59]; Renatus and Geldermann [60] }\end{array}$ \\
\hline Specific studies (33) & $\begin{array}{l}\text { Haberl and Geissler [11]; Sikkema et al. [28, 34]; Sommerhuber et al. [29, 61]; Gasol et al. [31]; Ariffin et al. [32]; Böttcher et al. } \\
\text { [33]; Parobek et al. [35]; Wolfslehner et al. [36]; Pehlken et al. [37]; Proskurina et al. [38]; Fraanje [62-64]; Haberl et al. [65]; } \\
\text { Dornburg et al. [66]; Sathre and Gustavsson [43]; Höglmeier et al. [67-69]; Bergeron [70, 71]; Canals et al. [72]; Ahmadi et al. } \\
\text { [73]; Ganzevles et al. [74]; Bais et al. [75]; Huysman et al. [76]; Kalt [77]; Nunes and Freitas [78]; Steubing et al. [79]; Taskhiri } \\
\text { et al. [80]; Zander et al. [81] }\end{array}$ \\
\hline
\end{tabular}

publication was written by Connelly and Koshland [50], who proposed a definition of consumption by introducing an exergy-based definition of material cycling and described how it quantifies the differences among three distinct categories of material reuse: upgrading, recirculation, and cascading.

Models and Methods Kim et al. [51] developed an allocation method for the cascade recycling system that addresses both the quality and quantity of a material used and takes the environmental impact of each life cycle into account. A method for estimating the expected utilization time for a material has been proposed by Yamashita et al. [52]. Mantau [10] introduced the method wood resource balance, and Knauf [53] questioned whether the model accurately reflects reality, proposing enhancements for the original wood resource balance model. Mellor et al. [54] developed a model for supporting decision-making on which material/product could be best used for specific additional purposes, and Vogtländer et al. [55] presented an LCA-based model that could be used to run integrated analyses of the product chain, its recycling systems, and its waste treatment systems at the endof-life of a product.

Methodological and Conceptual Frameworks Dornburg and Faaij [56] defined a methodological framework for different cascade chains of biomass. A conceptual framework regarding the cascade use of biomass has been provided by Keegan et al. [57], and McLaren et al. [58] developed a methodological framework for the environmental assessment of material recycling systems. A six-step approach for a more sustainable use of primary wood was developed by Lafleur and Fraanje [59].

Summing up the results of specific studies that have been conducted on $\mathrm{CU}$, the research can be divided into studies in which the economic, environmental, and/or social impacts were assessed; industrial ecology studies in which the flows, stock, and potentials of several regions were analyzed; and cascading chains of different types of resources.

Impact assessments Sikkema et al. [34] analyzed the GHG contributions of cascade use vs. wood for energy. The additional effort that must be invested in terms of costs and $\mathrm{CO}_{2}$ equivalents due to logistics that are required for cascading has been discussed by Taskhiri et al. [80]. Höglmeier et al. $[68,69]$ assessed the environmental impacts of recovered wood vs. primary wood and identified the most efficient wood allocation in Bavaria. The factors that influence energy and carbon balances of biomass cascade chains have been analyzed by Sathre and Gustavsson [82]. Moreover, the environmental impacts of the life cycle stages of raw material supply and end-of-life pathways of WPCs have been assessed [29], and both an energy and climate impact assessment of waste wood recovery in Switzerland [71] and a sustainability impact assessment of small-diameter wood in Austria [36] have been performed.

Industrial Ecology Studies in which biomass flows in Austria [77], wood biomass flows in 11 world regions [75], or raw wood flows in Slovakia [35] were modeled and assessed fall into this category. Bergeron [70] modeled the wood resource and waste wood metabolism over one century in Switzerland and assessed its impact on climate change of cascading vs. renewable energy production. In other studies, the carbon stock in particle board and fiberboard for the Spanish wood industry was quantified [72] or the land use change and socioeconomic metabolism in Austria were analyzed by modeling four land use scenarios for 2020 [65]. Haberl and Geissler [11] analyzed the interference of societies in the natural energy flow of ecosystems and proposed to maximize the socioeconomic advantage gained from using a limited amount of biomass harvested by cascade utilization.

Cascading Chains of Different Types of Resources Using recovered wood from building deconstruction for cascading [67] and WPCs as an intermediate step in the cascade chain of biomass [61] have been illustrated. Fraanje [62, 63] discussed the possible cascade chains of pine wood and the possibilities to achieve higher-quality applications of poplar wood. 


\section{Cascading Utilization and Circular Economy}

In this section, the results from Lieder and Rashid [24••], who performed a review on CE publications, are compared to the results of the current analysis. By comparing the demographic research focus of both reviews (Fig. 1), we noted that many of the $\mathrm{CE}$ and $\mathrm{CU}$ publications were geographically independent. Most of the CE publications focused on Asian countries, especially in China (54\%), unlike CU publications, in which the focus was placed mostly on European countries such as Germany (19\%) and the Netherlands (10\%).

The number of publications issued per year on both concepts is illustrated in Fig. 2. The review of Lieder and Rashid [24••] includes articles published between 1991 and May 2015, whereas this review covers articles on CU from 1991 until December 2016. Despite this difference in the period analyzed, it can be seen that the research interest on $\mathrm{CU}$ and $\mathrm{CE}$ has steadily increased. The timelines differ in that the number of publications on $\mathrm{CU}$ appearing annually has increased rapidly from 2012 onwards, while the number of publications on CE steadily, but more slowly, increased after 2008.

As indicated previously, the concept of $\mathrm{CU}$ is primarily mentioned in the context of biomass or bio-based materials. Nevertheless, by screening the titles of the articles from the literature (Fig. 3), we could confirm that research on $\mathrm{CU}$ has focused strongly on renewable resources whereas research on $\mathrm{CE}$ has focused on a diversity of resources.

Figure 4 illustrates the research perspectives of publications about $\mathrm{CU}$ and $\mathrm{CE}$. Whereas research on $\mathrm{CU}$ was mostly done to examine the environmental impact or both resource scarcity and environmental impact, our results showed that most of the research on $\mathrm{CE}$ was conducted to examine resource scarcity and environmental impact. This conclusion was also reached by Lieder and Rashid [24••]. The results of our review of the literature revealed that publications written by researchers in European countries have focused more heavily on the environmental aspects of research on CU (93\%), while their Chinese counterparts have placed a stronger focus on the aspect of resource scarcity (82\%).

Comparing the results of the categories type of research and research field for publications about $\mathrm{CU}$ and $\mathrm{CE}$ allowed us to identify similarities between these concepts. Most studies on CU and CE have been specific studies, and the rest are review studies or development work where within both concepts, the relative numbers of each research type are roughly similarly distributed. Most CU and CE studies were conducted by researchers working in the research fields of the environmental sciences and industrial ecology, regardless of the geographical research focus. The numbers of $\mathrm{CU}$ and $\mathrm{CE}$ studies assigned to other research fields were quite similar, although many geographically-independent $\mathrm{CE}$ research papers could not be assigned to any research field (i.e., these were summarized under the category others). These parallels in terms of distribution among the categories described above indicate that the two concepts share many characteristics.

\section{Characteristics of Cascading Utilization}

The articles on CU were also analyzed to determine whether one or more of the $3 \mathrm{R}$ and waste hierarchy elements were mentioned. No consensus of when and how to use these terms was observed, as is the case with cascading. The terms recycling and reuse were often used for the same purpose and, furthermore, were often not defined properly [32, 33, 47].

The same observation was made for disposal. Disposal in the context of the waste hierarchy means that a resource has no

Fig. 1 Geographic research focus of the $\mathrm{CU}(n=57)$ literature from the current study, compared to the CE literature $(n=136)$ used by Lieder and Rashid [24••]

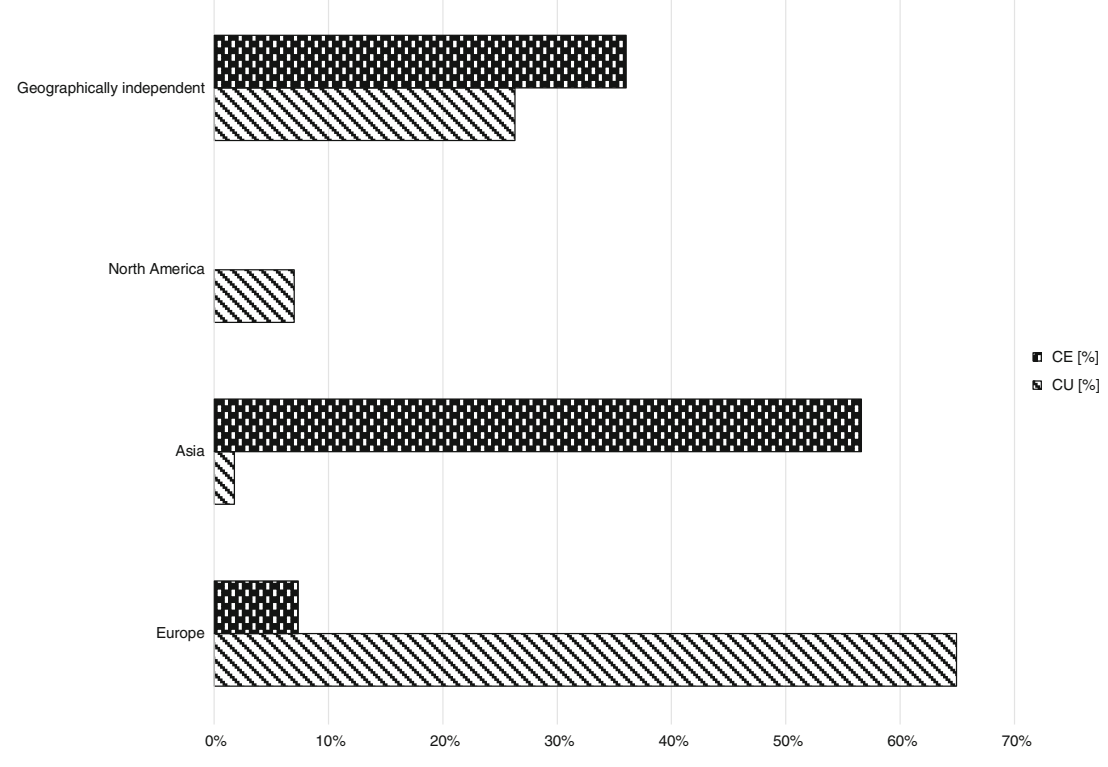


Fig. 2 Number of publications per year on CU $(n=57)$ and CE $(n=136)$. The CE literature is taken from the review of Lieder and Rashid [23]
30

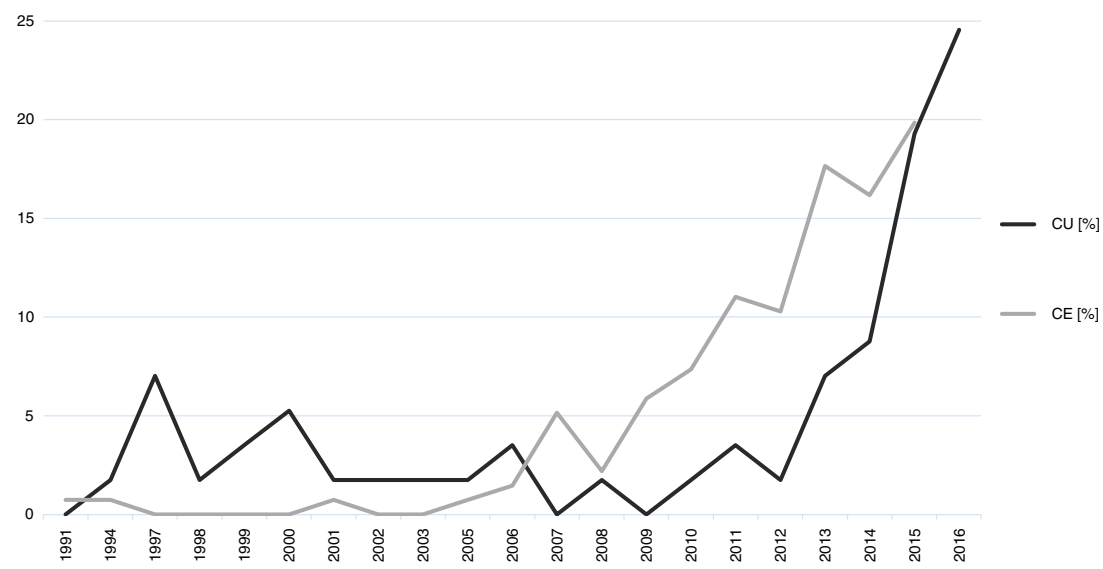

further application and, therefore, must be landfilled. For example, in the context of production companies, waste must be disposed of. Consequently, disposal was only counted as such when it was clear that the use according to the waste hierarchy was intended.

During the analysis of the publications on CU, we determined that the term reduce was mentioned not only in the context of resource management but also, for example, in the context of reducing emission, impacts, or energy. Although all these environmental issues are included in the broader understanding of the $\mathrm{CE}$ and waste management concepts, they are not directly included within the CU concept. Therefore, this term was only counted if it referred to a reduction in resource input.

The term recycle was used in almost all publications on $\mathrm{CU}$ (89\%) in addition to reduce and recovery (79\%) and reuse (74\%). The term disposal was only mentioned in $37 \%$ of publications (Fig. 5).
At least $25 \%$ of the articles on CU mentioned three to five of the $3 R$ and $W H$ elements (listed in Table 2), whereas about 7\% mentioned only one or two elements. The most frequently used combinations of the $3 R$ and $W H$ elements were "reuse and recycle" and "recycle and recovery" (72\%). All 3R elements were mentioned in $60 \%$ of the articles and all WH elements in only $25 \%$ of all publications on CU.

These results indicate that strong interrelations exist between the two concepts. To determine precisely what differentiates them from each other, we analyzed the articles on $\mathrm{CU}$ to identify to which extent they refer to the four cascading dimensions described by Sirkin and ten Houten [8].

The first cascading dimension resource quality can be described as "a function of the amount of embodied energy, the degree of structural organization and the chemical composition of a given resource [...] and also as a function of the effort required to produce or reproduce the quality. The higher the

Fig. 3 Types of resources

mentioned in the titles of publications of the present study on $\mathrm{CU}(n=57)$ and the $\mathrm{CE}$ $(n=136)$ literature analyzed in the review of Lieder and Rashid $[24 \cdot \bullet]$

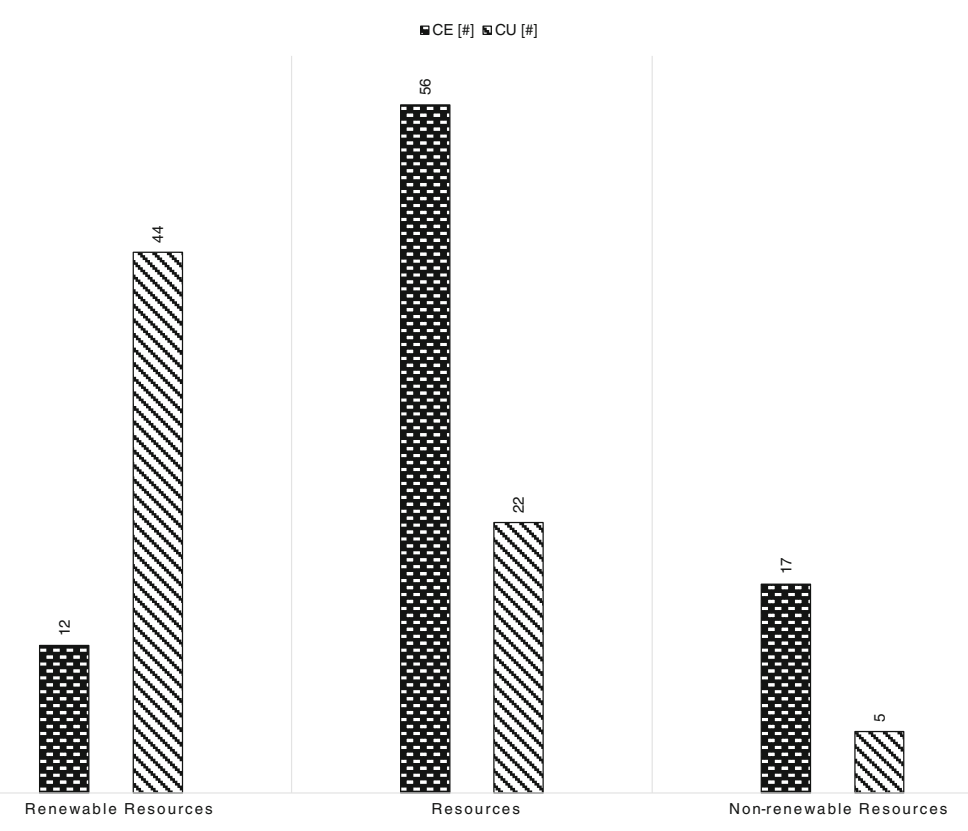


Fig. 4 Research perspective of $\mathrm{CU}(n=57)$ literature from the current study and the CE $(n=136)$ literature used by Lieder and Rashid [24]

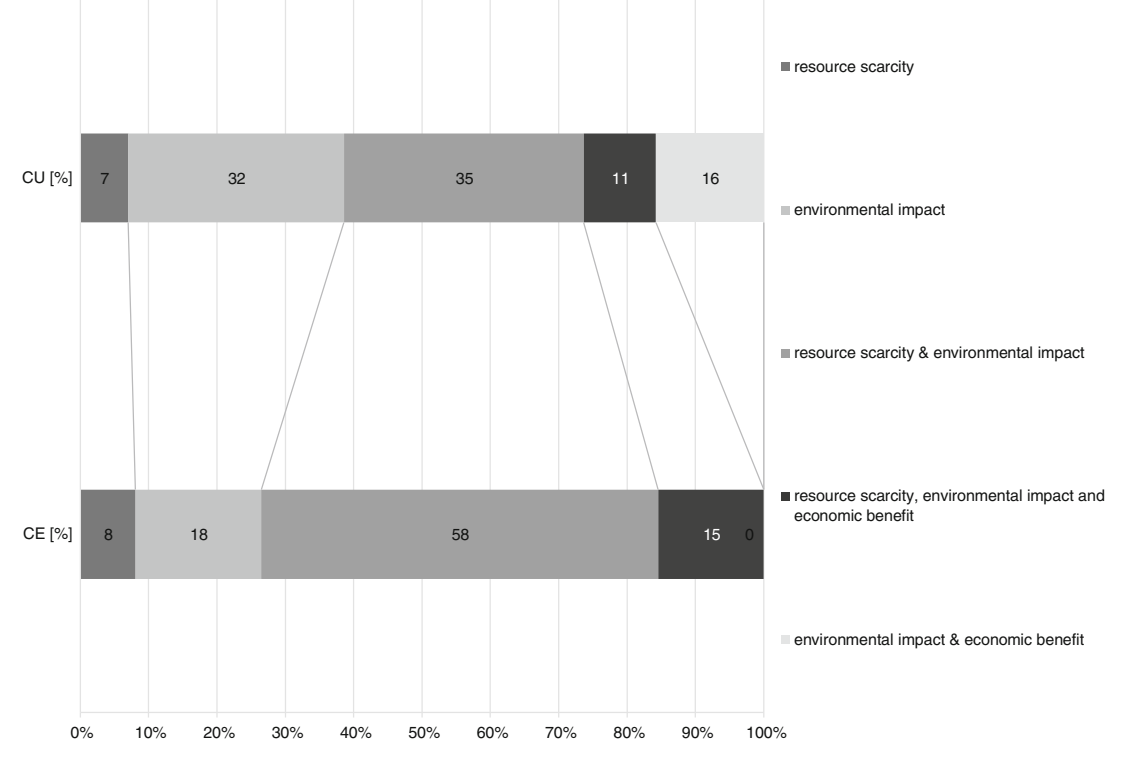

quality, the greater its potential to carry out more highly demanding tasks" [8, p. 216]. The quality loss per application should be minimized to increase the overall lifetime of a resource in use [62]. However, in a CE, materials should be designed in such a way that they can be recovered, remanufactured, and upgraded with a minimum investment of energy to maximize the conservation of value [83]. Some standards and regulations already include descriptions of quality classes for sorting waste paper [84] and waste wood [85] so that high-quality materials can be used for high-quality applications. This led us to the conclusion that the cascading dimension resource quality is already implemented in waste management practices to a certain extent. Moreover, this dimension was mentioned frequently in the literature on $\mathrm{CU}$ (i.e., $63 \%$ of the articles mentioned or referred to that dimension).

The cascading dimension utilization time refers to the extension of the service life of a resource in use. The Ellen MacArthur Foundation [83] states that the number of consecutive cycles and time spent in each cycle must be maximized to extend product life. Obviously, the utilization time increases if a material is reused or recycled, so we can conclude that this dimension is important in both concepts. Nevertheless, three quarters of the articles referred to that dimension to some extent, and more than half referred to both dimensions utilization time and resource quality.
Fig. $53 \mathrm{R}$ and WH elements mentioned in the $\mathrm{CU}$ literature $(n=57)$

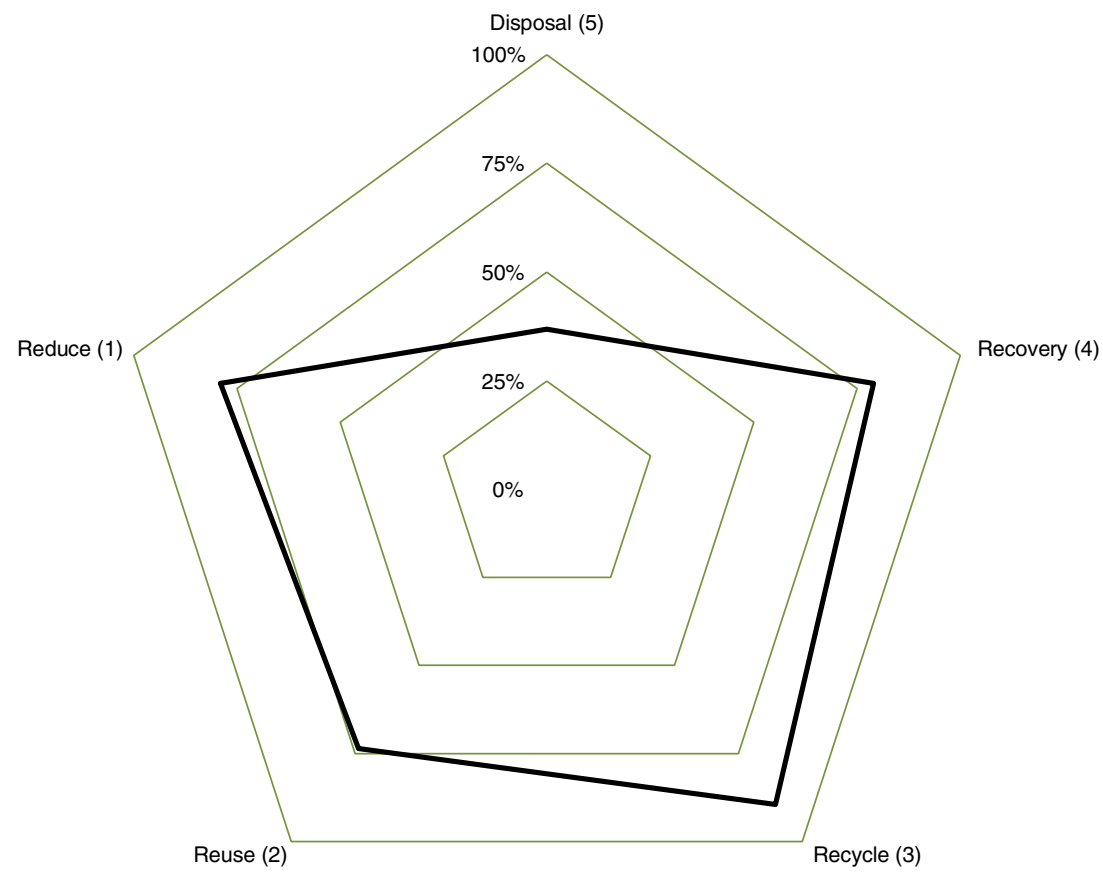


Fig. 6 Cascading use within the circular economy (own illustration, adapted from Ellen MacArthur Foundation [25])

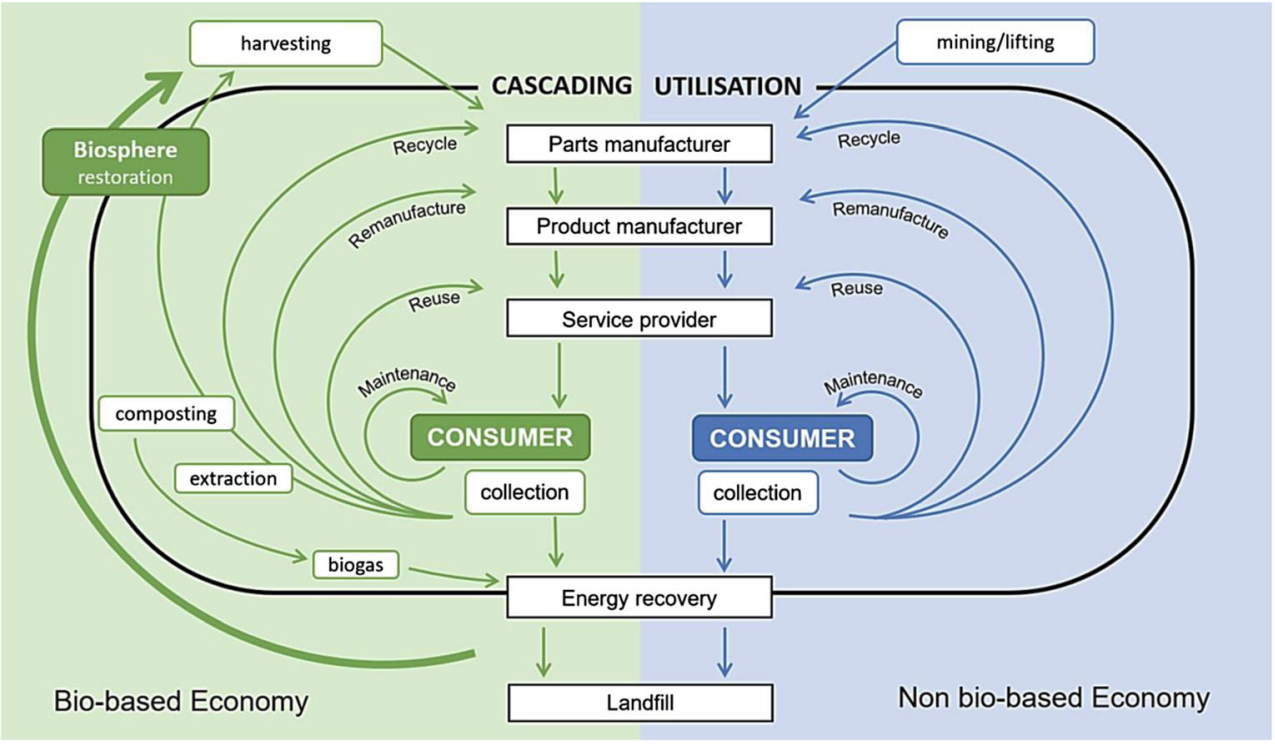

The dimension resource salvageability basically describes how a resource can be recirculated, for instance, by recirculating, regenerating, or reprocessing resources such that they reenter higher levels of the cascade or are introduced into other or new cascade cycles, respectively. It also includes a description of a process used to evaluate the optimal recirculation pathway [8]. Thirty-nine percent of the articles on CU covered this dimension. However, the CE concept describes a similar approach. Materials can be converted into new materials with higher quality and increased functionality [25] for use in other applications [83] or for the exchange of byproducts among industries [22].

The dimension consumption rate concerns the way the volume of resource consumption and resource regeneration is balanced by assessing the volume or rate of a resource flow [8]. Half of the articles on CU referred to the importance of sustainable consumption or included an assessment of a resource flow within a system and were, therefore, assigned to this dimension. The $\mathrm{CE}$ concept states that an industrial system should be restorative and regenerative and aim to eliminate waste. $\mathrm{CE}$ is recognized as being able to neutralize imbalances in the supply of and demand for natural resources [83].

\section{Discussion}

The results of our study clearly show that similarities between the $\mathrm{CU}$ and $\mathrm{CE}$ concepts exist. One resemblance is that both concepts apply similar utilization options after a product, component, or material is used for a period. The differences in the research on $\mathrm{CU}$ and $\mathrm{CE}$ were most striking in terms of the geographical research focus (Fig. 1), the publication timeline (Fig. 2), and the materials considered (Fig. 3). The fact that a large number of publications on $\mathrm{CE}$ have been written by researchers in China (Fig. 1) can potentially be explained by the emergence of huge environmental, human health, and social problems that have evolved due to recent rapid, continuous economic development. For these reasons, Chinese researchers have demonstrated a high level of commitment towards CE [17•]. The literature on CU has tended to focus primarily on European countries. One possible explanation for this and for the fact that the number of publications rapidly increased from 2012 onwards (Fig. 2) is that the concept of cascading has recently appeared with a much higher frequency in policy papers. $\mathrm{CU}$ is being promoted as part of the European and German bioeconomy strategy $[2,86]$ as well as the European forest strategy [87]. Furthermore, CU has been mentioned several times in the progress report on the German national sustainability strategy [88], in the German resource efficiency program [89], and in several research projects on cascading $[4 \bullet, 5,90]$.

Although the studies on CE have primarily focused on various types of resources and studies on CU have focused mostly on renewable resources (Fig. 3), both concepts should theoretically be applicable to the management of all resources $[8,91]$. A potential explanation of why CU has mostly been mentioned in the context of wood or bio-based products and has placed a focus mainly on European countries is that the recent European policies not only promote a transition towards a bio-economy but also the use of biomass for renewable energy production [44]. One question that emerges is whether the resource should be used for material purposes first and only afterwards for energy production. Therefore, we conclude that European policies are partly responsible for the recent increase in the number of publications on $\mathrm{CU}$ and the focus on renewable resources that appears in publications on CU (Fig. 2).

In addition, the Ellen McArthur Foundation [25] also limits the application of CU only to the bio-based economy (left side in Fig. 6). However, based on the results of the 
present study, CU is a concept that includes the same endof-life utilization possibilities (recycling, reuse, up-cycling, and down-cycling) as CE and, therefore, can equally be applied in the bio-based as well as in the non-bio-based economy (black frame in Fig. 6). In other words, CU summarizes all end-of-life resource management options within one term.

The reliability and validity of results obtained through systematic literature reviews always have certain typical limitations. These limitations must also be considered when interpreting the outcomes of this study. Most importantly, the fact that scientific publications on certain aspects of $\mathrm{CU}$ or $\mathrm{CE}$ are lacking does not necessarily imply that these aspects do not exist in research or practice. For a variety of reasons, certain aspects may not have been the subject of research, or the results may not have been published as peer-reviewed papers in journals [92]. Our results only covered research conducted (and published) up until 2016. In addition, only two databases (Scopus and ScienceDirect) were searched and, therefore, certain publications may not have been included in the study. However, given that the analysis resulted in the identification of a pool of 57 papers that were published between 1990 and 2016, we consider this review to provide a comprehensive coverage of the topic. A small weakness may also be the choice of a single reference for comparing $\mathrm{CU}$ literature with $\mathrm{CE}$ literature. Also, the $\mathrm{CE}$ review from Lieder and Rashid [24••] is an empirical work and includes articles up to May 2015 only; more recent publications are not included.

\section{Conclusions}

Systematically examining the differences and/or similarities of $\mathrm{CU}$ and $\mathrm{CE}$ in scientific publications led us to the conclusion that the number of publications that provide a connection between the two concepts is surprisingly low. Only one editorial mentioned both concepts together, and the concepts never appeared together in the abstracts of the research papers examined. Although the term CE appeared much earlier in the literature, the concept of $\mathrm{CU}$ appeared to gain popularity in the scientific literature from the early 1990s to the mid-2000s. Thereafter, the use of CE became more common, followed by a recent resurgence in the use of $\mathrm{CU}$, with the usage of the terms reaching parity (in term of numbers of publications) by 2015 .

In this review, a systematic approach was taken to identify the similarities and differences between these two concepts. The concept of $\mathrm{CU}$ is more highly focused on resource management, whereas the concept of CE provides a more holistic view (Fig. 6). In publications on $\mathrm{CE}$, a diversity of resources was considered, whereas publications on $\mathrm{CU}$ tended to focus on bio-based materials. As a matter of fact, the concept of $\mathrm{CU}$ mostly refers to the use of resources from high- to low-value products [79]. In contrast, CE focuses on how to keep the resources in the system and minimize the use of primary resources.

Despite these differences, CU perfectly fits into the $\mathrm{CE}$ concept. This was clearly demonstrated by the fact that the cascading dimensions have already been considered within the $\mathrm{CE}$ concept to some extent, and that waste management terminology is widely used within the literature on CU. The concept of CU, hereby, places a focus on various end-of-life utilization options (i.e., waste hierarchy elements). Therefore, the term CU may be used whenever one or more of these utilization possibilities are included.

$\mathrm{CU}$ is part of a $\mathrm{CE}$, in which resources are kept within the economy for as long as possible. Based on this observation, the fact that the concept of $\mathrm{CU}$ is not actively integrated into that of CE can be explained by the fact that established concepts are difficult to export out of specific research communities. The observed inconsistencies in the usage of the terms reuse and recycling may be typical indicators for a lack of interdisciplinary exchange. Furthermore, with reference to the differences observed in geographic focus, European policy papers may have had a vital influence on the preferred terms used in research and vice versa.

Our findings indicated that actively integrating the $\mathrm{CU}$ into the $\mathrm{CE}$ concept could strengthen both concepts in multiple ways. The concept of CU, for example, could be used to communicate with members of a general audience, as it may be somewhat easier to understand than the concept of CE. With specific reference to wood and other bio-based resources, $\mathrm{CU}$ could also be considered to represent a concept that forms a connection between $\mathrm{CE}$ and the bio-economy, fostering an inclusive, circular bio-economic vision in the future.

The development studies identified in the literature on $\mathrm{CU}$ could be used to improve the concept of CE as well [10,51, $54,58]$ and vice versa. Hence, we suggest that CU should be considered a basic concept within $\mathrm{CE}$ and particularly in the circular bio-economy, in which investigations are performed on raw material efficiency performance over multiple-use phases. Nevertheless, future work is needed to combine these concepts or integrate CU within CE.

Acknowledgements Open access funding provided by University of Graz. We thank Lieder M. for providing data from his circular economy review, Oswald Y. for validating the analysis, Asada R. for helpful discussions conducted during the analysis, and Crockett $\mathrm{S}$. for copyediting the text.

\section{Compliance with Ethical Standards}

Conflict of Interest Mair C. and Stern T. have no conflicts of interest to declare.

Human and Animal Rights and Informed Consent This article does not contain any studies with human or animal subjects performed by any of the authors. 


\section{Appendix}

The key terms used for this literature review are listed in Table 4. Since the term cascading is used in several contexts, for instance, energy or water, the identification of relevant literature on $\mathrm{CU}$ was rather complex. Due to time constraints, the term cascade in combination with all resource types was excluded from the search (over 15,000 documents).

Table 4 Search matrix for literature review

\begin{tabular}{lll}
\hline Key terms & Cascading & Utilization \\
\hline Synonyms & Cascade & Use \\
& Cascades & Chain \\
& Cascaded & \\
Type of resource & Wood & Biomass \\
& Bio-based materials & Resource \\
& Material & Product \\
& Waste & Renewable/non- \\
& & renewable resource \\
\hline
\end{tabular}

The filters in Scopus and ScienceDirect were set as follows:

- Time boundaries: 1991 to 2016

- Language: English

- Document type: article, review, and editorial

- Search range: title, abstract, and key words

The following search queries were used:

Scopus: ("cascad* use" OR "cascad* utilization" OR "cascad* chain") AND (wood OR bio* OR material OR *esource OR product OR waste).

ScienceDirect: (cascad* (use OR utilization OR chain)) AND (wood OR bio* OR material OR *esource OR product OR waste).

This resulted in the identification of 113 documents in Scopus and 584 in ScienceDirect. Therefore, the science fields in ScienceDirect were limited to those listed in Table 5. Before excluding fields, the search was performed for each science field, and only those without any relevant publication results were excluded. This resulted in the identification of $213 \mathrm{doc}-$ uments in ScienceDirect. Then, all abstracts were screened again to determine whether the research objectives of the present study were met. The remaining articles were subsequently screened to determine whether the term cascading was mentioned more than three times in the entire article.

To verify that no relevant $\mathrm{CU}$ article was missing, the references of the identified articles were screened as well as those by authors who quoted the identified articles in their work. This resulted in the identification of 57 articles, which were then reviewed.
Table 5 Science fields included in the literature search in ScienceDirect

\begin{tabular}{|c|c|}
\hline Included & Excluded \\
\hline $\begin{array}{l}\text { Agricultural and biological } \\
\text { science }\end{array}$ & Arts and humanities -0 results \\
\hline Earth and planetary science & $\begin{array}{l}\text { Biochemistry, genetics, and molecular } \\
\text { biology }\end{array}$ \\
\hline $\begin{array}{l}\text { Economic, econometrics, } \\
\text { and finance }\end{array}$ & Business, management, and accounting \\
\hline Energy & Chemical engineering \\
\hline Environmental science & Chemistry \\
\hline \multirow[t]{16}{*}{ Social science } & Computer science \\
\hline & Decision science \\
\hline & Engineering \\
\hline & Immunology and microbiology \\
\hline & Linguistics \\
\hline & Material science \\
\hline & Mathematics \\
\hline & Medicine and dentistry \\
\hline & Neuroscience \\
\hline & Nursing and health professions \\
\hline & $\begin{array}{l}\text { Pharmacology, toxicology, and } \\
\text { pharmaceutical science }\end{array}$ \\
\hline & Philosophy \\
\hline & Physics and astronomy \\
\hline & Psychology \\
\hline & Sports and recreation \\
\hline & $\begin{array}{l}\text { Veterinary science and veterinary } \\
\text { medicine }\end{array}$ \\
\hline
\end{tabular}

Open Access This article is distributed under the terms of the Creative Commons Attribution 4.0 International License (http:// creativecommons.org/licenses/by/4.0/), which permits unrestricted use, distribution, and reproduction in any medium, provided you give appropriate credit to the original author(s) and the source, provide a link to the Creative Commons license, and indicate if changes were made.

\section{References}

Papers of particular interest, published recently, have been highlighted as:

- Of importance

•- Of major importance

1. Bezama A. Let us discuss how cascading can help implement the circular economy and the bio-economy strategies. Waste Manag Res. 2016;34:593-4. https://doi.org/10.1177/0734242X16657973.

2. European Commission. Innovating for sustainable growth: a bioeconomy for europe. Brüssel: 2012.

3. CaReWood. Cascading recovered wood-a WoodWisdom Net+ project. 2014. http://carewood.eu/index.html. Accessed 3 Apr 2017.

4. European Commission. Cascades: study on the optimised cascading use of wood. Brüssel: 2016. This study provides a review on 
cascading literature in order to define the concept of cascading utilization.

5. Dammer L, Bowyer C, Breitmayer E, Eder A, Nanni S, Allen B, et al. Mapping study on cascading use of wood products. Switzerland: 2016.

6. Böhmer S, Gössl M, Krutzler T, Pölz W. Effiziente nutzung von holz: kaskade versus verbrennung. Wien: 2014.

7. Arnold K, von Geibler J, Bienge K, Stachura C, Borbonus S, Kristof K. Kaskadennutzung von nachwachsenden Rohstoffen: Ein Konzept zur Verbesserung der Rohstoffeffizienz und Optimierung der Landnutzung. Wuppertal: 2009.

8. Sirkin T, ten Houten M. The cascade chain. Resour Resour Conserv Recycl. 1994;10:213-77. https://doi.org/10.1016/0921-3449(94) 90016-7.

9. Webster E. The circular economy: a wealth of flows. 1st ed. United Kingdom: Ellen MacArthur Foundation Publishing; 2015.

10. Mantau U. Wood flow analysis: quantification of resource potentials,cascades and carbon effects. Biomass Bioenergy. 2015;79:28-38. https://doi.org/10.1016/j.biombioe.2014.08. 013.

11. Haberl H, Geissler S. Cascade utilization of biomass: strategies for a more efficient use of a scarce resource. Ecol Eng. 2000;16:111-21.

12. European Commission. Monthly note, industrial policy indicators and analysis, June 2013. 2015. http://ec.europa.eu/DocsRoom/ documents/10121/attachments/1/translations/en/renditions/native. Accessed 27 Mar 2017.

13. European Commission. Towards a circular economy: a zero waste programme for Europe 2014.

14. European Commission. Closing the loop-an EU action plan for the Circular Economy. Brussels: 2015.

15. Boulding K. The economy of the coming spaceship earth. In: Jarret $\mathrm{H}$, editor. Environmental quality in a growing economy. Baltimore: Johns Hopkins Press; 1966.

16. George DA, Lin BC-A, Chen Y. A circular economy model of economic growth. Environ Model Softw. 2015;73:60-3. https:// doi.org/10.1016/j.envsoft.2015.06.014.

17. Ghisellini P, Cialani C, Ulgiati S. A review on circular economy: the expected transition to a balanced interplay of environmental and economic systems. J Clean Prod. 2016;114:11-32. https://doi.org/ 10.1016/j.jclepro.2015.09.007. This research review provides a good overview on the origin and principles of circular economy and publications at the micro, meso, and macro levels

18. Pearce DW, Turner RK. Economics of natural resources and the environment. New York: Harvester Wheatsheaf; 1990.

19. Jawahir IS, Bradley R. Technological elements of circular economy and the principles of 6R-based closed-loop material flow in sustainable manufacturing. Procedia CIRP. 2016;40:103-8. https://doi.org/ 10.1016/j.procir.2016.01.067.

20. Yuan Z, Bi J, Moriguichi Y. The circular economy: a new development strategy in China. J Ind Ecol. 2006;10:4-8. https://doi.org/10. 1162/108819806775545321.

21. Feng Z, Yan N. Putting a circular economy into practice in China. Sustain Sci. 2007;2:95-101. https://doi.org/10.1007/s11625-0060018-1.

22. Mathews JA, Tan H. Progress toward a circular economy in China. J Ind Ecol. 2011;15:435-57. https://doi.org/10.1111/j.1530-9290. 2011.00332.x.

23. Yong R. The circular economy in China. J Mater Cycles Waste Manag. 2007;9:121-9. https://doi.org/10.1007/s10163-007-0183-z.

24.• Lieder M, Rashid A. Towards circular economy implementation: a comprehensive review in context of manufacturing industry. $\mathrm{J}$ Clean Prod. 2016;115:36-51. https://doi.org/10.1016/j.jclepro. 2015.12.042. This review presents an overview of scientific publications on circular economy. Moreover, it served as a basis for comparing the concept of cascading utilization with circular economy in this study
25. Ellen MacArthur Foundation. Towards the circular economy: economic and business rational for an accelerated transition. 2013.

26. Mayring P. Qualitative Inhaltsanalyse. In: Mey G, Mruck K, editors. Handbuch Qualitative Forschung in der Psychologie. Wiesbaden: VS Verlag für Sozialwissenschaften/Springer Fachmedien Wiesbaden GmbH Wiesbaden; 2010. p. 601-13.

27. VERBI Software GmbH. MAXQDA. 2017. http://www.maxqda. com/. Accessed 24 Aug 2017

28. Sikkema R, Junginger M, van Dam J, Stegeman G, Durrant D, Faaij A. Legal harvesting, sustainable sourcing and cascaded use of wood for bioenergy: their coverage through existing certification frameworks for sustainable Forest management. Forests. 2014;5:2163-211. https://doi.org/10.3390/ f5092163.

29. Sommerhuber PF, Wenker JL, Rüter S, Krause A. Life cycle assessment of wood-plastic composites: analysing alternative materials and identifying an environmental sound end-of-life option. Resour Resour Conserv Recycl. 2017;117:235-48. https://doi.org/10.1016/ j.resconrec.2016.10.012.

30. EU. Directive 2008/98/EC of the European Parliament and of the Council of 19 November 2008 on waste and repealing certain directives. Off J EU. 2008:L 312.

31. Gasol C, Farreny R, Gabarrell XB, Rieradevall JB. Life cycle assessment comparison among different reuse intensities for industrial wooden containers. Int J Life Cycle Assess. 2008;13:421-31. https://doi.org/10.1007/s11367-008-0005-0.

32. Ariffin H, Nishida H, Hassan MA, Shirai Y. Chemical recycling of polyhydroxyalkanoates as a method towards sustainable development. Biotechnol J. 2010;5:484-92. https://doi.org/10.1002/biot. 200900293.

33. Böttcher H, Freibauer A, Scholz Y, Gitz V, Ciais P, Mund M, et al. Setting priorities for land management to mitigate climate change. Carbon Balance and Management. 2012; https://doi.org/10.1186/ 1750-0680-7-5.

34. Sikkema R, Junginger M, McFarlane P, Faaij A. The GHG contribution of the cascaded use of harvested wood products in comparison with the use of wood for energy — a case study on available forest resources in Canada. Environ Sci Pol. 2013;31:96-108. https://doi.org/10.1016/j.envsci.2013.03.007.

35. Parobek J, Paluš H, Kaputa V, Šupín M. Analysis of wood flows in Slovakia. BioResour. 2014;9:6453-62.

36. Wolfslehner B, Huber P, Lexer MJ. Smart use of small-diameter hardwood - a forestry-wood chain sustainability impact assessment in Austria. Scand J For Res. 2013;28:184-92. https://doi.org/10. 1080/02827581.2012.686626.

37. Pehlken A, Madena K, Aden C, Klenke T. Forming stakeholder alliances to unlock alternative and unused biomass potentials in bioenergy regions. J Clean Prod. 2016;110:66-77. https://doi.org/ 10.1016/j.jclepro.2015.05.052.

38. Proskurina S, Sikkema R, Heinimö J, Vakkilainen E. Five years left-how are the EU member states contributing to the $20 \%$ target for EU's renewable energy consumption; the role of woody biomass. Biomass Bioenergy. 2016;95:64-77. https://doi.org/10. 1016/j.biombioe.2016.09.016.

39. Geldermann J, Kolbe LM, Krause A, Mai C, Militz H, Osburg V-S, et al. Improved resource efficiency and cascading utilisation of renewable materials. Journal of Cleaner Production. 2016;110:18. doi: https://doi.org/10.1016/j.jclepro.2015.09.092.

40. Teuber L, Osburg V-S, Toporowski W, Militz H, Krause A. Wood polymer composites and their contribution to cascading utilisation. J Clean Prod. 2016;110:9-15. https://doi.org/10.1016/j.jclepro. 2015.04.009.

41. de Besi M, McCormick K. Towards a bioeconomy in Europe: national, regional and industrial strategies. Sustain For. 2015;7: 10461-78. https://doi.org/10.3390/su70810461. 
42. Brosowski A, Thrän D, Mantau U, Mahro B, Erdmann G, Adler P, et al. A review of biomass potential and current utilisation - status quo for 93 biogenic wastes and residues in Germany. Biomass Bioenergy. 2016:257-72. https://doi.org/10.1016/j.biombioe.2016. 10.017 .

43. Gustavsson L., Sathre R. Energy and CO2 analysis of wood substitution in construction. Clim Chang. 2011;105:129-53. https://doi. org/10.1007/s10584-010-9876-8 .

44. Knauf M. Waste hierarchy revisited - an evaluation of waste wood recycling in the context of EU energy policy and the European market. Forest Policy Econ. 2015;54:58-60. https://doi.org/10. 1016/j.forpol.2014.12.003.

45. Sikkema R, Dallemand JF, Matos CT, van der Velde M, SanMiguel-Ayanz J. How can the ambitious goals for the EU's future bioeconomy be supported by sustainable and efficient wood sourcing practices? Scand J For Res. 2016; https://doi.org/10.1080/ 02827581.2016.1240228.

46. Lippke B, Oneil E, Harrison R, Skog K, Gustavsson L, Sathre R. Life cycle impacts of forest management and wood utilization on carbon mitigation: knowns and unknowns. Carbon Management. 2011;2:303-33. https://doi.org/10.4155/cmt.11.24.

47. Brunet-Navarro P, Jochheim H, Muys B. Modelling carbon stocks and fluxes in the wood product sector: a comparative review. Glob Chang Biol. 2016;22:2555-69. https://doi.org/10.1111/gcb.13235.

48. van Lancker J, Wauters E, van Huylenbroeck G. Managing innovation in the bioeconomy: an open innovation perspective. Biomass Bioenergy. 2016;90:60-9. https://doi.org/10.1016/j.biombioe. 2016.03.017.

49. Reijnders L. A normative strategy for sustainable resource choice and recycling. Resour Conserv Recycl. 2000;28:121-33. https:// doi.org/10.1016/S0921-3449(99)00037-3.

50. Connelly L, Koshland CP. Two aspects of consumption: using an exergy-based measure of degradation to advance the theory and implementation of industrial ecology. Resour Conserv Recycl. 1997;19:199-217. https://doi.org/10.1016/S09213449(96)01180-9.

51. Kim S, Hwang T, Lee KM. Allocation for cascade recycling system. Int J LCA. 1997;2:217-22. https://doi.org/10.1007/ BF02978418.

52. Yamashita H, Kishino H, Hanyu K, Hayashi C, Abe K. Circulation indices: new tools for analyzing the structure of material cascades. Resour Resour Conserv Recycl. 2000:85-104.

53. Knauf M. An analysis of wood market balance modeling in Germany. Forest Policy Econ. 2015;50:319-26. https://doi.org/10. 1016/j.forpol.2014.09.013.

54. Mellor W, Wright E, Clift R, Azapagic A, Stevens G. A mathematical model and decision-support framework for material recovery, recycling and cascaded use. Chem Eng Sci. 2002;57:4697-713. https://doi.org/10.1016/S0009-2509(02)00282-8.

55. Vogtländer JG, Brezet HC, Hendriks CF. Allocation in recycling systems: an integrated model for the analyses of environmental impact and market value. Int J Life Cycle Assess. 2001;6:344-55.

56. Dornburg V, Faaij APC. Cost and CO2-emission reduction of biomass cascading: methodological aspects and case study of SRF poplar. Clim Chang. 2005;71:373-408. https://doi.org/10.1007/ s10584-005-5934-z.

57. Keegan D, Kretschmer B, Elbersen B, Panoutsou C. Cascading use: a systematic approach to biomass beyond the energy sector. Biofuels Bioprod Biorefin. 2013:193-206.

58. McLaren J, Parkinson S, Jackson T. Modelling material cascadesframeworks for the environmental assessment of recycling systems. Resour Resour Conserv Recycl. 2000;31:83-104. https://doi.org/ 10.1016/S0921-3449(00)00073-2.

59. Lafleur MC, Fraanje PJ. Towards sustainable use of the renewable resource wood in the Netherlands - a systematic approach. Resour Resour Conserv Recycl. 1997;20:19-29.
60. Renatus F, Geldermann J. Multi-criteria decision support based on iterative comparisons with reference points. J Clean Prod. 2016:99-108.

61. Sommerhuber PF, Welling J, Krause A. Substitution potentials of recycled HDPE and wood particles from post-consumer packaging waste in wood-plastic composites. Waste Manag. 2015;46:76-85. https://doi.org/10.1016/j.wasman.2015.09.011.

62. Fraanje PJ. Cascading of pine wood. Resour Resour Conserv Recycl. 1997;19:21-8.

63. Fraanje PJ. Poplar wood for purlins; an evaluation of options and environmental aspects. Holz Roh Werkst. 1998;56:163-9.

64. Fraanje PJ. Use of wood in new Dutch one family dwellings since 1969. Holz Roh Werkst. 1999;57:407-17.

65. Haberl H, Erb K-H, Krausmann F, Adensam H, Schulz NB. Landuse change and socio-economic metabolism in Austria-part II: land-use scenarios for 2020. Land Use Policy. 2003;20:21-39. https://doi.org/10.1016/S0264-8377(02)00049-2.

66. Dornburg V, Faaij A, Patel M, Turkenburg WC. Economics and GHG emission reduction of a PLA bio-refinery system - combining bottom-up analysis with price elasticity effects. Resour Resour Conserv Recycl. 2006;46:377-409. https://doi.org/10.1016/j. resconrec.2005.08.006.

67. Höglmeier K, Weber-Blaschke G, Richter K. Potentials for cascading of recovered wood from building deconstruction - a case study for south-east Germany. Resour Resour Conserv Recycl. 2013;78: 81-91. https://doi.org/10.1016/j.resconrec.2013.07.004.

68. Höglmeier K, Weber-Blaschke G, Richter K. Utilization of recovered wood in cascades versus utilization of primary wood-a comparison with life cycle assessment using system expansion. Int J Life Cycle Assess. 2014;19:1755-66. https://doi.org/10. 1007/s11367-014-0774-6.

69. Höglmeier K, Steubing B, Weber-Blaschke G, Richter K. LCAbased optimization of wood utilization under special consideration of a cascading use of wood. J Environ Manag. 2015;152:158-70. https://doi.org/10.1016/j.jenvman.2015.01.018.

70. Bergeron FC. Assessment of the coherence of the Swiss waste wood management. Resour Resour Conserv Recycl. 2014;91: 62-70. https://doi.org/10.1016/j.resconrec.2014.07.011.

71. Bergeron FC. Energy and climate impact assessment of waste wood recovery in Switzerland. Biomass Bioenergy. 2016;94:245-57. https://doi.org/10.1016/j.biombioe.2016.09.009.

72. Canals GG, Valero E, Picos J, Voces R. Carbon storage in HWP. Accounting for Spanish particleboard and fiberboard. Forest Systems. 2014;23:225-35. https://doi.org/10.5424/fs/201423204046.

73. Ahmadi L, Young SB, Fowler M, Fraser RA, Achachlouei MA. A cascaded life cycle: reuse of electric vehicle lithium-ion battery packs in energy storage systems. Int J Life Cycle Assess. 2015; https://doi.org/10.1007/s11367-015-0959-7.

74. Ganzevles J, Asveld L, Osseweijer P. Extending bioenergy towards smart biomass use issues of social acceptance at Park Cuijk, the Netherlands. Energy, Sustainability and Society. 2015;5:271-83. https://doi.org/10.1186/s13705-015-0053-9.

75. Bais ALS, Lauk C, Kastner T, Erb K. Global patterns and trends of wood harvest and use between 1990 and 2010. Ecol Econ. 2015;119:326-37. https://doi.org/10.1016/j.ecolecon.2015.09.011.

76. Huysman S, Debaveye S, Schaubroeck T, Meester SD, Ardente F, Mathieux F, et al. The recyclability benefit rate of closed-loop and open-loop systems: a case study on plastic recycling in Flanders. Resour Resour Conserv Recycl. 2015;101:53-60. https://doi.org/ 10.1016/j.resconrec.2015.05.014.

77. Kalt G. Biomass streams in Austria: drawing a complete picture of biogenic material flows within the national economy. Resour Resour Conserv Recycl. 2015;95:100-11. https://doi.org/10.1016/ j.resconrec.2014.12.006. 
78. Nunes J, Freitas H. An indicator to assess the pellet production per forest area. A case-study from Portugal. For Policy Econ. 2016;70: 99-105. https://doi.org/10.1016/j.forpol.2016.05.022.

79. Steubing B, Mutel C, Suter F, Hellweg S. Streamlining scenario analysis and optimization of key choices in value chains using a modular LCA approach. Int J Life Cycle Assess. 2016;21:510-22. https://doi.org/10.1007/s11367-015-1015-3.

80. Taskhiri MS, Garbs M, Geldermann J. Sustainable logistics network for wood flow considering cascade utilisation. J Clean Prod. 2016;110:25-39. https://doi.org/10.1016/j.jclepro.2015.09.098.

81. Zander S, Trang S, Kolbe LM. Drivers of network governance: a multitheoretic perspective with insights from case studies in the German wood industry. J Clean Prod. 2016;110:109-20. https:// doi.org/10.1016/j.jclepro.2015.03.010.

82. Sathre R, Gustavsson L. Energy and carbon balances of wood cascade chains. Resour Resour Conserv Recycl. 2006;47:332-55. https://doi.org/10.1016/j.resconrec.2005.12.008.

83. Ellen MacArthur Foundation. Towards a circular economy: business rationale for an accelerated transition. 2015.

84. CEN. Papier, Karton und Pappe - Europäische Liste der AltpapierStandardsorten. Wien: Austrian Standards Institute; 2014. p. 85.060.

85. AltholzV. Verordnung über Anforderungen an die Verwertung und Beseitigung von Altholz (Altholzverordnung e AltholzV, s.l); 2012.
86. Federal Ministry of Food and Agriculture. National policy strategy on bioeconomy: renewable resources and biotechnological processes as a basis for food, industry and energy: BMEL; 2014.

87. European Commission. A new EU forest strategy: for forests and the forest-based sector. 2013.

88. German Government. Fortschrittsbericht 2008 zur nationalen Nachhaltigkeitsstrategie: Für ein nachhaltiges Deutschland. Berlin: 2008.

89. BMUB. Deutsches Ressourceneffizienzprogramm (ProgRess): Programm zur nachaltigen Nutzung und zum Schutz der natürlichen Ressourcen. 2nd ed. Berlin: 2012.

90. Arnold K, Bienge K, von Geibler J, Ritthoff M, Targiel T, Zeiss C, et al. Klimaschutz und optimierter Ausbau erneuerbarer Energien durch Kaskadennutzung von Biomasse: Potenziale, Entwicklungen und Chancen einer integrierten Strategie zur stofflichen und energetischen Nutzung von Biomasse. 5th ed. Wuppertal: 2009.

91. Webster K, Johnson C, Blériot J, Gravis L, editors. A new dynamic 2: effective systems in a circular economy. Isle of Wight: Ellen MacArthur Foundation Publishing; 2016.

92. Lähtinen K, Toppinen A, Suojanen H, Stern T, Ranacher L, Burnard $\mathrm{M}$, et al. Forest sector sustainability communication in Europe: a systematic literature review on the contents and gaps. Curr Forestry Rep. 2017;5:1. https://doi.org/10.1007/s40725-017-0063-2. 